\title{
Assessment of Water Availability at Growth Stages of Rainfed kharif Rice in the Plains of West Bengal during 2020-2099 using Regional Climate Model Output
}

\author{
S. Mahato ${ }^{1 *}$, A. Saha ${ }^{1}$ and D. Majumder ${ }^{2}$ \\ ${ }^{1}$ Department of Agricultural Meteorology, ${ }^{2}$ Department of Agricultural Statistics, \\ $B C K V$, West Bengal, India \\ *Corresponding author
}

\section{A B S T R A C T}

\begin{tabular}{|l|} 
K e y w o r d s \\
Rainfall, Stable \\
rainfall, Standard \\
Meteorological \\
Week (SMW), Rice \\
\hline Article Info \\
\hline $\begin{array}{l}\text { Accepted: } \\
17 \text { March } 2019 \\
\text { Available Online: } \\
\text { 10 April } 2019\end{array}$ \\
\hline
\end{tabular}

\section{Keywords}

Rainfall, Stable Meteorological Week (SMW), Rice

.

Available Online:

\begin{abstract}
An attempt has been made in the present paper to study the agroclimatic potential for the future periods from 2020 to 2099 with A1B-GHG ( Greenhouse Gas Emissions Scenarios) emission scenarios which have been derived from PRECIS (Providing Regional Climate for impact Studies). Rainfall data was used to estimate decadal change in the stable rainfall at various growth stages of transplanted rice of five different representative stations pertaining to Terai, Old Alluvial, New Alluvial, Red \& Laterite, and Coastal Saline zones of West Bengal. Rainfall information was also utilized for determining earliest date for sowing upland crop and transplanted rice. Decadal averages of various agroclimatic indices were tested through Analysis of variance (ANOVA) for discovering significant differences. Analysis showed that distribution of stable rainfall over various growth stages of rice though showed a distinct reduction with advancement of transplanting time for 29 SMW to 35 SMW, relative differences of such resources over the future decades were inconsistent.
\end{abstract}

\section{Introduction}

Crop planning, particularly under rainfed condition, need thorough appraisal of the agroclimatic resources in general and rainfall and resultant crop water availability, in particular. Since such planning varies with locale and soil physical factors, a uniform plan cannot be advocated for a large region, like the plains of West Bengal. So, separate appraisal for each agroclimatic zones is very much needed. There are many literatures that have already been conducted using historical meteorological records which are suitable for assessment of the present climatic situation and its potential for Rice productivity. However, as the threat of climate change looming large in the horizon, these assessments may not be sufficient for the future periods, for which assessment of Rice production is very urgent. With the advent of various Global Circulation Models (GCMs) and Regional Circulation Models (RCMs), synthetic future daily weather data on various parameters are available for the entire global region, at very narrow coordinates even up to the end of this century. 
The climate in the state of West Bengal is tropical and humid except in the northern hilly region. The average rainfall in the state is about $1750 \mathrm{~mm}$. (NABARD, 2014). 75$80 \%$ of the rainfall occur during the four months i.e., within June to September of the monsoon season, followed by four to five months dry period during November to March with having very low rainfall for crop production. Crop production during pre-kharif season i.e., February to May with jute and aus rice sown during mid-April to May may not be successful when there is delay in the onset of monsoon. The state as a whole, experiences dry sub-humid to humid climate. The warm rainy season is climatically suited to most tropical crops like rice, jute etc. (Ghosh, 1991).

Projections of rainfall in West Bengal for mid century i.e 2050s indicates that there is no change in monsoon (June-July-AugustSeptember) rainfall in the entire region, except, an increase is indicated in the southern Sundarbans region of the South 24 Parganas and in Eastern part of Purulia. In the winters (October-November-December), however, the scenario changes, the rainfall decreases in most parts of southern Bengal, no change is seen in eastern parts of Purulia and in Coochbehar and Jalpaiguri. In summers, the rainfall is likely to decrease northwards starting from Bankura, Purulia, Burdwan, with no change in Paschim Medinipur, Hooghly, Howrah, and North 24 Parganas, and an increase in summer rainfall in the south 24 Parganas and Uttar Medinipur. The rainfall however tends to increase in the entire region by the end of the century, except in January-February period, when the rainfall is likely to decrease in the entire alluvial region from Dakshin Dinajpur in the north to Bankura, Howrah, Kolkata, and northern parts of North 24 Parganas and Paschim Medinipur in the South (Anon, 2013).

\section{Materials and Methods}

Climate projections from 2020 through 2099 have been derived from PRECIS (Providing Regional Climate for Impact Studies), which is portable version of the HadCM3 model, developed to run with a grid resolution of $0.44^{\circ} \times 0.44^{\circ}$ (Jones et al., 2004). The climate change scenarios are driven by the GHG emission scenarios-A1B. For each climate grid daily data on rainfall, minimum temperature, maximum temperature, solar radiation, relative humidity and wind speed were available in the dataset. Five representative locations each from one agroclimatic region, viz., Terai (Jalpaiguri), Old alluvial (Raiganj), new alluvial (Krishnanagar), Red \& Laterite (Purulia) and Coastal saline zone (Canning) in the plains of West Bengal were selected for analysis.

\section{Data analysis}

The climatological analyses in this study were on Standard Meteorological Week (SMW) basis. To make the period $1^{\text {st }}$ January to $7^{\text {th }}$ January each year as $1^{\text {st }}$ SMW, an adjustment was made in the said table. In this week format, the $9^{\text {th }}$ SMW would consist of 8 days from $26^{\text {th }}$ February to $4^{\text {th }}$ March in the leap years, however, in other years it would consist of 7 days. Last week of the year, $52^{\text {nd }}$ SMW, would always consist of 8 days $\left(24^{\text {th }}\right.$ December to $31^{\text {st }}$ December).

\section{Stable rainfall for rice}

Considering 3-4 mm daily ET loss and 3-4 $\mathrm{mm}$ daily percolation loss from rice field in the eastern Indian region, Singh and Singh (2000) have assumed that a weekly rainfall of $50 \mathrm{~mm}$ is sufficient / stable to meet the water requirement of rice crop. Since the average bund height maintained by the farmer is around $50 \mathrm{~mm}$, which is maximum allowable submergence, it was considered that any 
weekly rainfall above this quantity is ineffective and is going to be lost as run-off (Saha, 2006). Taking this into consideration, effective rainfall $(50 \mathrm{~mm} /$ week $)$ for each week of kharif rice crop growing season of the entire database was calculated. Entire growth period of rice after transplanting was divided into three stages, viz., vegetative (6 weeks), reproductive (4 weeks) and maturity (4 weeks). However, during maturity stage rainwater deficit was analyzed only up to 3 weeks since later weeks require dryness for good harvesting operation. Cumulative stable rainfall for each of the three crop growth stages, were summed up for 5 different possible transplanting periods (29th, $31^{\text {st }}, 33^{\text {rd }}$ and $35^{\text {th }}$ SMW).

\section{Statistical analysis}

\section{Decadal trends}

To compare the decadal trends of various parameters, data corresponding to 8 decades like 2020-29, 2030-2039 etc were summarized and compared using one way analysis of variance. "F" values were tested for significance and SE (m) and L.S.D. (5\% level) values were calculated, corresponding to each parameter, using standard statistical methods.

\section{Results and Discussion}

\section{Decadal changes in the stable rainfall at various growth stages of transplanted rice}

Accumulated stable rainfall during vegetative, reproductive, maturity as well as during entire growing stage for the rainfed kharif rice crop transplanted from 29 to 35 Standard Meteorological Week (SMW), averaged over decades from 2020s through 2090s for different agroclimatic zones of West Bengal are presented in Tables 1, 2, 3, 4 .
During vegetative stage, the decadal averages of stable rainfall were not found to be much variable and statistically significant. During vegetative stage, against a stable rainfall requirement of $300 \mathrm{~mm}$ for 6 weeks period, the agroclimatic zones are likely to receive around 220 to $297 \mathrm{~mm}$ across various transplanting weeks and different future periods up to 2099. If the crop is transplanted up to $33 \mathrm{SMW}$, it is likely to receive maximum stable rainfall in Terai region which is followed by Red and Laterite and Coastal saline zone and least amount will be available in Old and New alluvial zone. With delay in transplanting from 29 SMW, there is a slight reduction in stable rainfall up to 33 SMW and the reduction is steeper when the transplanting is delayed up to 35 SMW. If the transplanting is extended up to $31^{\text {st }} \mathrm{SMW}$, the vegetative stage of the crop is likely to be affected most by deficit of stable rainfall in the Red and Laterite zones of West Bengal. Though there is little variation in the decadal averages of the stable rainfall during this period, no definite trends with the advancement of the decade towards 2090s were confirmed.

If transplanted during 29 SMW (July 16 to 22 ), the reproductive stage of rice crop is most likely to receive rainfall which is very near to its optimum requirement of $200 \mathrm{~mm}$ and the extent of reduction, if any, may be to the extent of $25 \%$. The status of such water availability pattern is consistent among the entire agroclimatic zones studied for entire future decades from 2020 s to 2090s. If the transplanting is delayed up to 31 SMW (July 31 to Aug 5), the extent of reduction of stable rainfall can maximum be a nominal rate of $25 \%$, which is consistent across the agroclimatic zones in future decades. Therefore, data presented in the tables revealed that transplanted rice in different agroclimatic zones of West Bengal will be almost free from water stress during 
reproductive stage for all the future decades up to 2090s. If the transplanting is delayed by another fortnight, that is 33 SMW (Aug 13rd to $19^{\text {th }}$ Aug) a reduction in stable rainfall to the extent of $25 \%$ to $50 \%$ (against $200 \mathrm{~mm}$ ideal for the stage) can be obtained during various future decades across all agroclimatic zones studied. However, the extent of reduction due to such delay is likely to be much higher in Red and Laterite zone as compared to that in other agroclimatic zones.

However, under situation of extreme late transplanting at $35 \mathrm{SMW}$ the extent of reduction in the stable rainfall availability is likely to be reduced to be $50 \%$ to $85 \%$ across all the agroclimatic zones and future decades with the extents of such reduction are steeper in Red and Laterite zone. There found to be a little variation in the decadal averages of the stable rainfall during this period but in most of the cases no definite trend with the advancement of the decade towards 2090s were confirmed.

Under complete rainfed condition the maturity stage of rice crop will definitely receive reduced stable rainfall across the agroclimatic zones and over future decadal periods. When the crop is transplanted up to 31 SMW, the extent of shortage in stable rainfall during this stage is likely to the tune of 15 to $50 \%$ but, if the transplanting is further delayed up to $33 \mathrm{SMW}$ (13rd Aug to 19th Aug) or 35 SMW (Aug 27th to 2nd Sep) the extent of stable rainfall shortage may be to the tune of 80 to $95 \%$ and it is consistent across agroclimatic zones and future decades. Decadal averages of stable rainfall during this stage did not show any significant trend over the future period up to 2090s.

When the decadal changes of the total stable rainfall during the growing season of rice were compared, it was revealed that the decadal variation was statistically significant for all possible transplanting scenarios up to 35 SMW in Terai zone of West Bengal. The decade of 2080s is likely to receive highest stable rainfall which is statistically different from that of first three decades up to 2040s. However, decadal trend were statistically at par for rest of the agroclimatic zones studied.

If transplanted during 29 SMW, rice crop, in its entire growth period, likely to receive shortage of stable rainfall only to the extent of 6 to $25 \%$ which is increased up to 13 to $33 \%$ for transplanting on 31 SMW, 25 to $45 \%$ for 33 SMW and 42 to $57 \%$ when transplanting is delayed extremely up to $35 \mathrm{SMW}$. The variation of the stable rainfall over the decades for different growth stages of Rice are plotted on Figure 1.

Considering stage wise availability of stable rainfall of different growth stages of transplanted rice, it was revealed from the above tables that the amount of rain water deficit is in the order, maturity stage > reproductive stage $>$ vegetative stage. When studied across agroclimatic zones, it is evident that pattern of relative water deficit during different stages with delay in transplanting is almost similar which indicates similar temporal pattern of rain fall distribution during crop growth stages across the agroclimatic zones studied.

Considering the criteria of weekly stable rainfall as described by Singh and Singh (2000), Saha (2006) estimated stable rainfall for rice under different transplanting scenario for various locations of New Alluvial zone of West Bengal using historical database of rainfall at different climatic risk level which also showed similar temporal pattern of stable rainfall availability under different transplanting scenario. 


\begin{tabular}{|c|r|r|r|r|r|r|r|r|}
\hline $\begin{array}{c}\text { Table.1 Decadal change of stable rainfall (mm) during vegetative stage of rice transplanted in } \\
\text { different meteorological weeks (Kharif) in the agroclimatic zones of West Bengal }\end{array}$ \\
\hline \multirow{2}{*}{ Decades } & \multicolumn{3}{|c|}{ Terai Zone } \\
& 29SMW & 31SMW & 33SMW & 35SMW & 29SMW & 31SMW & 33SMW & 35 SMW \\
\hline 2020s & 295.6 & 299.1 & 295.9 & 272.9 & 257.5 & 263.0 & 268.8 & 249.6 \\
\hline $\mathbf{2 0 3 0 s}$ & 295.3 & 292.2 & 293.7 & 272.4 & 265.3 & 266.4 & 277.0 & 252.7 \\
\hline $\mathbf{2 0 4 0 s}$ & 297.6 & 294.4 & 291.9 & 267.2 & 262.2 & 258.9 & 264.3 & 243.0 \\
\hline $\mathbf{2 0 5 0 s}$ & 296.0 & 298.7 & 294.3 & 291.0 & 261.3 & 262.5 & 262.9 & 268.1 \\
\hline $\mathbf{2 0 6 0 s}$ & 298.2 & 297.6 & 293.6 & 284.5 & 264.3 & 261.1 & 256.0 & 259.5 \\
\hline $\mathbf{2 0 7 0 s}$ & 285.1 & 289.1 & 292.1 & 277.0 & 241.6 & 259.0 & 265.6 & 261.8 \\
\hline $\mathbf{2 0 8 0 s}$ & 297.8 & 295.8 & 295.8 & 290.5 & 265.4 & 255.4 & 265.6 & 262.4 \\
\hline $\mathbf{2 0 9 0 s}$ & 296.4 & 295.4 & 292.2 & 279.9 & 252.5 & 262.1 & 268.1 & 253.7 \\
\hline & & & & & & & & \\
\hline SE(m) & 3.0 & 2.5 & 3.0 & 6.6 & 8.8 & 8.1 & 7.7 & 9.7 \\
\hline LSD(0.05) & NS & NS & NS & NS & NS & NS & NS & NS \\
\hline
\end{tabular}

\begin{tabular}{|c|r|r|r|r|r|r|r|r|}
\hline \multirow{2}{*}{ Decades } & \multicolumn{3}{|c|}{ New Alluvial Zone } & \multicolumn{4}{c|}{ Red and laterite Zone } \\
\cline { 2 - 11 } & 29SMW & 31SMW & 33SMW & 35SMW & 29SMW & 31SMW & 33SMW & 35SMW \\
\hline $\mathbf{2 0 2 0 s}$ & 246.4 & 238.2 & 245.4 & 234.3 & 278.5 & 266.0 & 256.3 & 228.1 \\
\hline $\mathbf{2 0 3 0 s}$ & 263.9 & 254.3 & 260.1 & 237.3 & 279.1 & 270.4 & 267.2 & 227.9 \\
\hline $\mathbf{2 0 4 0 s}$ & 259.5 & 241.5 & 244.0 & 232.8 & 281.5 & 266.2 & 260.0 & 227.2 \\
\hline $\mathbf{2 0 5 0 s}$ & 252.7 & 252.3 & 235.7 & 231.8 & 278.0 & 273.8 & 248.5 & 237.9 \\
\hline $\mathbf{2 0 6 0 s}$ & 240.3 & 240.3 & 237.8 & 236.4 & 261.4 & 260.8 & 251.2 & 226.3 \\
\hline $\mathbf{2 0 7 0 s}$ & 248.3 & 261.3 & 265.5 & 241.4 & 283.1 & 288.0 & 279.5 & 238.5 \\
\hline $\mathbf{2 0 8 0}$ & 253.1 & 231.2 & 234.1 & 234.0 & 280.3 & 257.5 & 260.3 & 236.5 \\
\hline $\mathbf{2 0 9 0}$ & 251.5 & 242.0 & 235.7 & 220.3 & 272.7 & 251.4 & 247.3 & 227.0 \\
\hline & & & & & & & & \\
\hline SE(m) & 12.5 & 12.1 & 12.5 & 12.6 & 8.3 & 9.2 & 10.0 & 13.4 \\
\hline LSD(0.5) & NS & NS & NS & NS & NS & NS & NS & NS \\
\hline
\end{tabular}

\begin{tabular}{|c|r|r|r|r|}
\hline \multirow{2}{*}{ Decades } & \multicolumn{4}{|c|}{ Coastal Saline Zone } \\
\cline { 2 - 5 } & 29SMW & 31SMW & 33SMW & 35SMW \\
\hline 2020s & 274.5 & 268.0 & 266.7 & 242.9 \\
\hline $\mathbf{2 0 3 0 s}$ & 281.7 & 280.7 & 280.8 & 257.9 \\
\hline $\mathbf{2 0 4 0 s}$ & 274.0 & 264.6 & 270.5 & 243.2 \\
\hline $\mathbf{2 0 5 0 s}$ & 281.2 & 280.7 & 266.8 & 263.5 \\
\hline $\mathbf{2 0 6 0 s}$ & 274.2 & 269.9 & 257.4 & 242.7 \\
\hline $\mathbf{2 0 7 0 s}$ & 279.1 & 283.4 & 281.1 & 248.4 \\
\hline $\mathbf{2 0 8 0 s}$ & 278.4 & 266.3 & 268.3 & 253.6 \\
\hline $\mathbf{2 0 9 0 s}$ & 276.0 & 270.0 & 261.3 & 239.8 \\
\hline SE(m) & 6.5 & 6.8 & 8.2 & 10.8 \\
\hline LSD(0.05) & NS & NS & NS & NS \\
\hline
\end{tabular}




\begin{tabular}{|c|r|r|r|r|r|r|r|r|}
\hline $\begin{array}{c}\text { Table.2 Decadal change of stable rainfall (mm) during reproductive stage of rice transplanted in } \\
\text { different meteorological weeks (Kharif) in the agroclimatic zones of West Bengal }\end{array}$ \\
\hline \multirow{3}{*}{ Decades } & \multicolumn{3}{|c|}{ Terai Zone } \\
& 29SMW & 31SMW & 33SMW & 35SMW & 29SMW & 31SMW & 33SMW & 35 SMW \\
\hline $\mathbf{2 0 2 0 s}$ & 196.0 & 173.6 & 110.1 & 48.2 & 178.7 & 164.6 & 98.4 & 43.1 \\
\hline $\mathbf{2 0 3 0 s}$ & 193.9 & 176.3 & 114.8 & 48.9 & 181.6 & 166.8 & 106.5 & 48.9 \\
\hline $\mathbf{2 0 4 0 s}$ & 193.3 & 170.4 & 106.6 & 42.5 & 177.5 & 158.3 & 95.4 & 35.2 \\
\hline $\mathbf{2 0 5 0 s}$ & 195.0 & 191.0 & 127.2 & 54.9 & 176.3 & 182.3 & 123.1 & 52.7 \\
\hline $\mathbf{2 0 6 0 s}$ & 194.9 & 185.5 & 140.6 & 70.6 & 178.3 & 169.6 & 128.5 & 63.4 \\
\hline $\mathbf{2 0 7 0 s}$ & 192.6 & 177.2 & 145.1 & 84.1 & 181.0 & 168.6 & 142.0 & 88.1 \\
\hline $\mathbf{2 0 8 0 s}$ & 197.4 & 193.2 & 148.0 & 78.6 & 178.0 & 183.2 & 128.2 & 58.1 \\
\hline $\mathbf{2 0 9 0 s}$ & 195.0 & 180.9 & 134.9 & 67.0 & 176.8 & 165.2 & 122.5 & 58.4 \\
\hline & & & & & & & & \\
\hline SE(m) & 2.8 & 6.4 & 10.9 & 11.3 & 6.0 & 8.3 & 12.2 & 11.3 \\
\hline LSD(0.05) & NS & NS & 30.83 & NS & NS & NS & NS & NS \\
\hline
\end{tabular}

\begin{tabular}{|c|r|r|r|r|r|r|r|r|}
\hline \multirow{2}{*}{ Decades } & \multicolumn{4}{|c|}{ New Alluvial Zone } & \multicolumn{4}{c|}{ Red and laterite Zone } \\
\cline { 2 - 10 } & 29SMW & 31SMW & 33SMW & 35SMW & 29SMW & 31SMW & 33SMW & 35SMW \\
\hline $\mathbf{2 0 2 0 s}$ & 166.7 & 156.0 & 107.5 & 59.1 & 167.8 & 142.2 & 84.6 & 46.9 \\
\hline $\mathbf{2 0 3 0 s}$ & 169.1 & 157.7 & 109.2 & 58.1 & 172.2 & 140.8 & 86.5 & 48.1 \\
\hline $\mathbf{2 0 4 0 s}$ & 164.8 & 155.8 & 106.6 & 49.9 & 169.8 & 144.2 & 88.1 & 38.6 \\
\hline $\mathbf{2 0 5 0 s}$ & 154.2 & 146.5 & 115.0 & 58.6 & 161.7 & 148.9 & 104.9 & 46.5 \\
\hline $\mathbf{2 0 6 0 s}$ & 164.3 & 150.3 & 118.7 & 67.3 & 166.4 & 135.6 & 94.6 & 48.3 \\
\hline $\mathbf{2 0 7 0 s}$ & 177.0 & 146.3 & 128.3 & 92.2 & 181.3 & 140.5 & 98.7 & 65.5 \\
\hline $\mathbf{2 0 8 0 s}$ & 158.6 & 164.6 & 127.5 & 71.2 & 169.3 & 160.9 & 97.8 & 46.4 \\
\hline $\mathbf{2 0 9 0 s}$ & 145.6 & 148.5 & 124.4 & 76.0 & 155.5 & 153.5 & 119.3 & 62.7 \\
\hline & & & & & & & & \\
\hline SE(m) & 9.7 & 10.4 & 12.7 & 10.8 & 8.9 & 11.9 & 15.2 & 11.2 \\
\hline LSD(0.05) & NS & NS & NS & NS & NS & NS & NS & NS \\
\hline
\end{tabular}

\begin{tabular}{|c|r|r|r|r|}
\hline \multirow{2}{*}{ Decades } & \multicolumn{4}{|c|}{ Coastal Saline Zone } \\
\cline { 2 - 5 } & 29SMW & 31SMW & 33SMW & 35SMW \\
\hline $\mathbf{2 0 2 0 s}$ & 181.4 & 153.2 & 103.0 & 64.5 \\
\hline $\mathbf{2 0 3 0 s}$ & 185.7 & 165.4 & 110.3 & 53.8 \\
\hline $\mathbf{2 0 4 0 s}$ & 180.3 & 155.8 & 103.1 & 54.9 \\
\hline $\mathbf{2 0 5 0 s}$ & 177.4 & 166.5 & 126.2 & 61.8 \\
\hline $\mathbf{2 0 6 0 s}$ & 171.1 & 150.5 & 120.2 & 68.2 \\
\hline $\mathbf{2 0 7 0 s}$ & 183.1 & 152.5 & 125.7 & 89.1 \\
\hline $\mathbf{2 0 8 0}$ & 176.3 & 169.3 & 125.6 & 69.4 \\
\hline $\mathbf{2 0 9 0 s}$ & 165.6 & 155.8 & 126.6 & 76.6 \\
\hline SE(m) & 6.8 & 9.8 & 13.3 & 11.1 \\
\hline LSD(0.05) & NS & NS & NS & NS \\
\hline
\end{tabular}




\begin{tabular}{|c|r|r|r|r|r|r|r|r|}
\hline $\begin{array}{c}\text { Table.3 Decadal change of stable rainfall (mm) during maturity stage of rice transplanted in } \\
\text { different meteorological weeks (Kharif) in the agroclimatic zones of West Bengal }\end{array}$ \\
\hline \multirow{3}{*}{ Decades } & \multicolumn{3}{|c|}{ Terai Zone } \\
\cline { 2 - 11 } & 29SMW & 31SMW & 33SMW & 35SMW & 29SMW & 31SMW & 33SMW & 35 SMW \\
\hline $\mathbf{2 0 2 0 s}$ & 94.3 & 38.8 & 19.9 & 17.4 & 83.7 & 32.7 & 22.5 & 24.5 \\
\hline $\mathbf{2 0 3 0 s}$ & 101.7 & 43.0 & 14.7 & 9.2 & 94.4 & 41.6 & 14.8 & 6.9 \\
\hline $\mathbf{2 0 4 0 s}$ & 90.6 & 35.8 & 10.4 & 7.3 & 84.8 & 33.0 & 6.4 & 11.2 \\
\hline $\mathbf{2 0 5 0 s}$ & 119.2 & 53.4 & 28.9 & 10.7 & 111.3 & 51.0 & 27.1 & 15.1 \\
\hline $\mathbf{2 0 6 0 s}$ & 124.2 & 64.9 & 24.4 & 16.9 & 114.5 & 56.3 & 26.1 & 23.2 \\
\hline $\mathbf{2 0 7 0 s}$ & 122.6 & 70.9 & 34.8 & 16.7 & 116.7 & 71.1 & 34.1 & 16.8 \\
\hline $\mathbf{2 0 8 0 s}$ & 126.6 & 73.5 & 30.2 & 10.0 & 108.4 & 55.5 & 20.7 & 10.0 \\
\hline $\mathbf{2 0 9 0 s}$ & 116.9 & 63.3 & 18.4 & 4.0 & 107.5 & 54.7 & 16.0 & 6.2 \\
\hline & & & & & & & & \\
\hline SE(m) & 8.5 & 10.8 & 6.1 & 4.8 & 10.1 & 10.5 & 6.6 & 6.5 \\
\hline LSD(0.05) & 23.85 & NS & NS & NS & NS & NS & NS & NS \\
\hline
\end{tabular}

\begin{tabular}{|c|r|r|r|r|r|r|r|r|}
\hline \multirow{2}{*}{ Decades } & \multicolumn{4}{|c|}{ New Alluvial Zone } & \multicolumn{4}{c|}{ Red and laterite Zone } \\
\cline { 2 - 10 } & 29SMW & 31SMW & 33SMW & 35SMW & 29SMW & 31SMW & 33SMW & 35SMW \\
\hline $\mathbf{2 0 2 0 s}$ & 91.4 & 52.7 & 29.6 & 25.3 & 75.4 & 38.0 & 31.0 & 22.3 \\
\hline $\mathbf{2 0 3 0 s}$ & 94.0 & 50.2 & 18.3 & 2.9 & 77.1 & 40.1 & 19.0 & 4.2 \\
\hline $\mathbf{2 0 4 0 s}$ & 95.1 & 44.1 & 14.9 & 16.3 & 77.1 & 37.3 & 9.3 & 7.9 \\
\hline $\mathbf{2 0 5 0 s}$ & 98.7 & 55.7 & 27.0 & 12.0 & 89.6 & 44.8 & 22.9 & 10.4 \\
\hline $\mathbf{2 0 6 0 s}$ & 106.7 & 58.5 & 25.4 & 18.4 & 85.9 & 43.5 & 19.7 & 18.3 \\
\hline $\mathbf{2 0 7 0 s}$ & 102.3 & 74.9 & 37.4 & 21.6 & 80.6 & 49.2 & 29.1 & 12.4 \\
\hline $\mathbf{2 0 8 0 s}$ & 105.7 & 67.6 & 30.4 & 19.6 & 81.5 & 43.4 & 22.1 & 14.3 \\
\hline $\mathbf{2 0 9 0 s}$ & 104.7 & 72.1 & 29.7 & 8.9 & 105.9 & 61.9 & 16.3 & 9.2 \\
\hline & & & & & & & & \\
\hline SE(m) & 10.7 & 9.7 & 7.6 & 6.1 & 12.5 & 10.4 & 6.6 & 5.8 \\
\hline LSD(0.05) & NS & NS & NS & NS & NS & NS & NS & NS \\
\hline
\end{tabular}

\begin{tabular}{|c|r|r|r|r|}
\hline \multirow{2}{*}{ Decades } & \multicolumn{4}{|c|}{ Coastal Saline Zone } \\
\cline { 2 - 5 } & 29SMW & 31SMW & 33SMW & 35SMW \\
\hline $\mathbf{2 0 2 0 s}$ & 86.9 & 54.4 & 31.8 & 19.1 \\
\hline $\mathbf{2 0 3 0 s}$ & 95.7 & 46.4 & 17.4 & 14.9 \\
\hline $\mathbf{2 0 4 0 s}$ & 89.2 & 49.0 & 21.4 & 18.0 \\
\hline $\mathbf{2 0 5 0 s}$ & 108.6 & 57.4 & 23.7 & 13.2 \\
\hline $\mathbf{2 0 6 0 s}$ & 105.0 & 58.2 & 23.9 & 18.3 \\
\hline $\mathbf{2 0 7 0 s}$ & 102.5 & 71.2 & 38.4 & 20.3 \\
\hline $\mathbf{2 0 8 0 s}$ & 101.0 & 64.1 & 30.0 & 18.1 \\
\hline $\mathbf{2 0 9 0}$ & 109.4 & 73.8 & 29.0 & 10.3 \\
\hline SE(m) & 10.6 & 9.8 & 7.3 & 6.3 \\
\hline LSD(0.05) & NS & NS & NS & NS \\
\hline
\end{tabular}




\begin{tabular}{c|r|r|r|r|r|r|r|r|}
\hline $\begin{array}{c}\text { Table.4 Decadal change of stable rainfall (mm) during whole growing stage of rice transplanted } \\
\text { in different meteorological weeks (Kharif) in the agroclimatic zones of West Bengal }\end{array}$ \\
\hline \multirow{2}{*}{$\begin{array}{c}\text { Decades } \\
\end{array}$} & \multicolumn{3}{|c|}{ Terai Zone } \\
\cline { 2 - 11 } Old Alluvial Zone \\
\hline $\mathbf{2 0 2 0 s}$ & 585.9 & 511.5 & 425.8 & 338.4 & 519.9 & 460.3 & 389.7 & 317.2 \\
\hline $\mathbf{2 0 3 0 s}$ & 590.9 & 511.5 & 423.2 & 330.5 & 541.2 & 474.7 & 398.2 & 308.4 \\
\hline $\mathbf{2 0 4 0 s}$ & 581.5 & 500.5 & 408.9 & 317.0 & 524.4 & 450.3 & 366.1 & 289.3 \\
\hline $\mathbf{2 0 5 0 s}$ & 610.2 & 543.1 & 450.4 & 356.6 & 549.0 & 495.8 & 413.0 & 335.8 \\
\hline $\mathbf{2 0 6 0 s}$ & 617.3 & 547.9 & 458.5 & 372.1 & 557.1 & 487.0 & 410.7 & 346.0 \\
\hline $\mathbf{2 0 7 0 s}$ & 600.4 & 537.3 & 472.1 & 377.7 & 539.2 & 498.7 & 441.6 & 366.7 \\
\hline $\mathbf{2 0 8 0 s}$ & 621.8 & 562.5 & 474.0 & 379.1 & 551.8 & 494.2 & 414.5 & 330.5 \\
\hline $\mathbf{2 0 9 0 s}$ & 608.3 & 539.6 & 445.5 & 350.8 & 536.8 & 482.0 & 406.6 & 318.2 \\
\hline & & & & & & & & \\
\hline SE(m) & 9.1 & 13.1 & 22.0 & 14.3 & 15.5 & 16.3 & 17.1 & 16.8 \\
\hline LSD(0.05) & 25.68 & 37.03 & 62.1 & 40.3 & NS & NS & NS & NS \\
\hline
\end{tabular}

\begin{tabular}{|c|r|r|r|r|r|r|r|r|}
\hline \multirow{2}{*}{ Decades } & \multicolumn{4}{|c|}{ New Alluvial Zone } & \multicolumn{4}{c|}{ Red and laterite Zone } \\
\cline { 2 - 10 } & 29SMW & 31SMW & 33SMW & 35SMW & 29SMW & 31SMW & 33SMW & 35SMW \\
\hline $\mathbf{2 0 2 0 s}$ & 504.4 & 446.8 & 382.5 & 318.7 & 521.7 & 446.2 & 371.9 & 297.3 \\
\hline $\mathbf{2 0 3 0 s}$ & 526.9 & 462.2 & 387.5 & 298.3 & 528.4 & 451.2 & 372.7 & 280.1 \\
\hline $\mathbf{2 0 4 0 s}$ & 519.4 & 441.4 & 365.5 & 298.9 & 528.4 & 447.6 & 357.4 & 273.5 \\
\hline $\mathbf{2 0 5 0 s}$ & 505.6 & 454.5 & 377.7 & 302.2 & 529.3 & 467.6 & 376.2 & 294.7 \\
\hline $\mathbf{2 0 6 0 s}$ & 511.3 & 449.1 & 381.8 & 322.1 & 513.6 & 439.9 & 365.5 & 292.8 \\
\hline $\mathbf{2 0 7 0 s}$ & 527.7 & 482.5 & 431.2 & 355.1 & 545.0 & 477.7 & 407.3 & 316.4 \\
\hline $\mathbf{2 0 8 0 s}$ & 517.3 & 463.3 & 391.9 & 324.7 & 531.1 & 461.8 & 380.2 & 297.2 \\
\hline $\mathbf{2 0 9 0 s}$ & 501.7 & 462.6 & 389.9 & 305.2 & 534.1 & 466.7 & 382.9 & 298.9 \\
\hline & & & & & & & & \\
\hline SE(m) & 22.4 & 21.9 & 22.1 & 20.5 & 18.3 & 21.1 & 21.7 & 20.6 \\
\hline LSD(0.05) & NS & NS & NS & NS & NS & NS & NS & NS \\
\hline
\end{tabular}

\begin{tabular}{|c|r|r|r|r|}
\hline \multirow{2}{*}{ Decades } & \multicolumn{4}{|c|}{ Coastal Saline Zone } \\
\cline { 2 - 5 } & 29SMW & 31SMW & 33SMW & 35SMW \\
\hline $\mathbf{2 0 2 0 s}$ & 542.7 & 475.6 & 401.5 & 326.5 \\
\hline $\mathbf{2 0 3 0 s}$ & 563.1 & 492.5 & 408.4 & 316.6 \\
\hline $\mathbf{2 0 4 0 s}$ & 543.5 & 469.3 & 395.0 & 316.1 \\
\hline $\mathbf{2 0 5 0 s}$ & 567.1 & 504.6 & 416.8 & 338.5 \\
\hline $\mathbf{2 0 6 0 s}$ & 550.3 & 478.6 & 401.4 & 329.2 \\
\hline $\mathbf{2 0 7 0 s}$ & 564.7 & 507.0 & 445.2 & 357.7 \\
\hline $\mathbf{2 0 8 0}$ & 555.7 & 499.6 & 423.9 & 341.0 \\
\hline $\mathbf{2 0 9 0}$ & 551.0 & 499.6 & 417.0 & 326.7 \\
\hline SE(m) & 16.8 & 18.8 & 19.7 & 19.3 \\
\hline LSD(0.05) & NS & NS & NS & NS \\
\hline
\end{tabular}


Fig.1 Decadal variation of the phasic distribution of stable rainfall for transplanted rice in 29 SMW for different agroclimatic zones of West Bengal from 2020s to 2090s
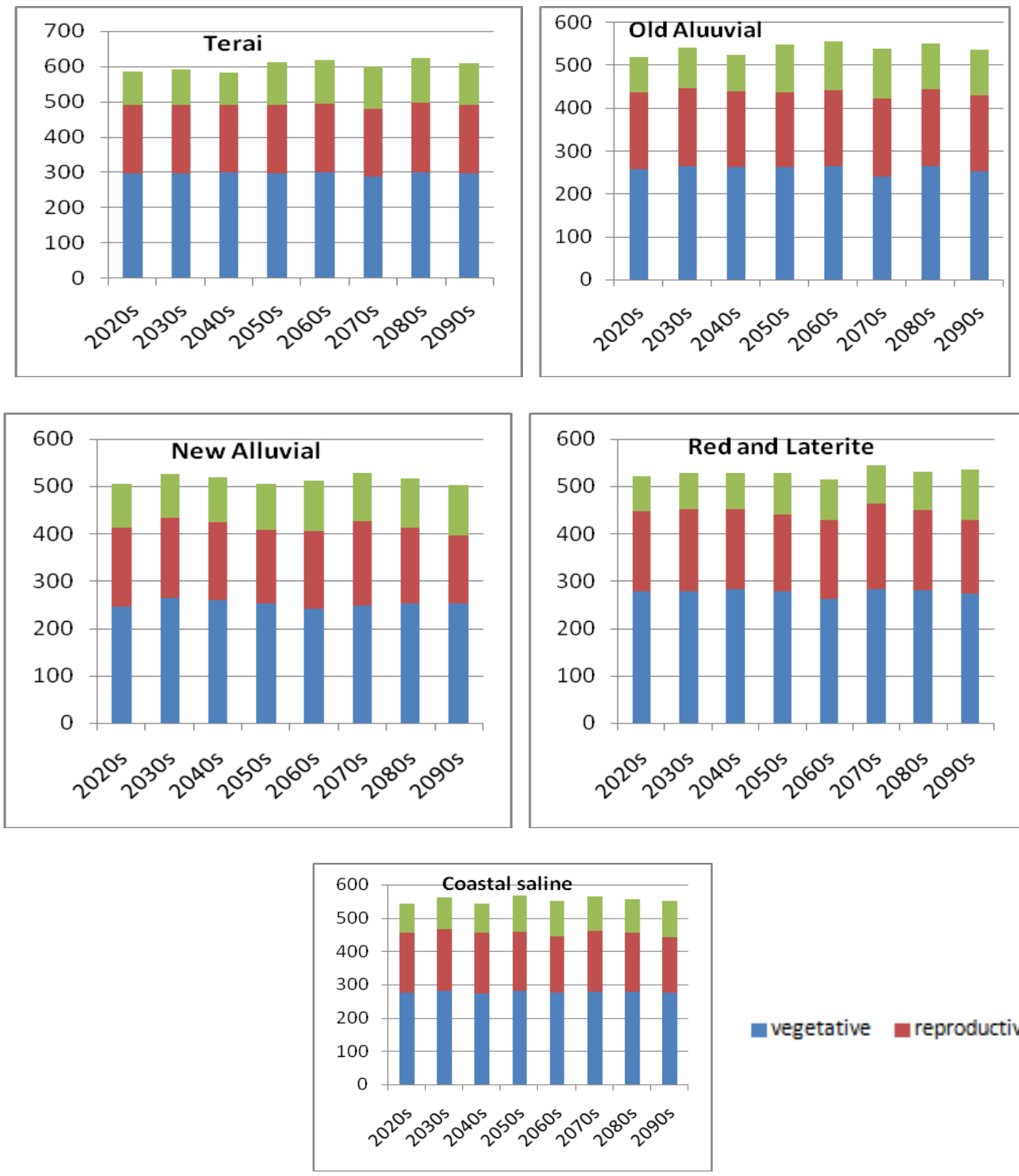

vegetative $\square$ reproductive maturity

If the crop is transplanted up to $33 \mathrm{SMW}$, it is likely to receive maximum stable rainfall in Terai region which is followed by Red and laterite and Coastal saline zone and least amount available in Old and New alluvial zone. With delay in transplanting from 29 SMW there is a slight reduction in stable rainfall up to 33 SMW and the reduction is steeper when the transplanting is delayed up to $35 \mathrm{SMW}$. If the transplanting is extended up to $31 \mathrm{SMW}$, the vegetative stage of the crop is likely to be affected most by deficit of stable rainfall in the Red and laterite zones of West Bengal.

If transplanted during 29 SMW (July $16^{\text {th }}$ to July $22^{\text {nd }}$ ), the reproductive stage of Rice crop is most likely to be received rainfall which is very near to its optimum requirement of 200 $\mathrm{mm}$ and the extent of reduction if any may be 
to the extent of $25 \%$. If transplanted during 33 SMW (Aug 13 to Aug 19) a reduction in stable rainfall to the extent of $25 \%$ to $50 \%$ (against $200 \mathrm{~mm}$ ideal for the stage) can be obtained during various future decades across all agro climatic region studies.

However, under situation of transplanting under extreme late condition of 35 SMW the extent of reduction in the stable rainfall availability is likely to be reduced to be $50 \%$ to $85 \%$ across all the agro climatic regions and future decades.

Under complete rainfed condition, if the rice crop is transplanted up to $31 \mathrm{SMW}$ the extent of shortage in stable rainfall during this stage is extent of 15 to $50 \%$ but if the transplanting is further delayed up to 33 SMW (13rd Aug to $19^{\text {th }} \mathrm{Aug}$ ) or $35 \mathrm{SMW}$ (Aug 27 to 2 Sep) this extent of stable rainfall shortage may be to the tune of 80 to $95 \%$ and it is consistent across agroclimatic zones and future decades.

Thus it can be concluded from the foregoing discussion that Reproductive and maturity stage of transplanted rice are likely to have stable rainfall shortage when transplanted beyond 31 and 29 SMW, respectively with maximum shortage in the Red and Laterite zone for the future periods without any definite trend.

\section{References}

Anon, (2013). West Bengal State Action Plan on Climate Change. Report of the Govt. of West Bengal. 191 pp.

Ghosh, S.P., 1991. Agricultural characteristics in the agro-climatic zones of Indian states: Agroclimatic zone specific research. ICAR. Pusa, New Delhi. 539 pp.

Jones, R.G., Noguer, M., Hassell, D.C., Hudson, D., Wilson, S.S., Jenkins, G.J. and Mitchell, J.F.B. (2004). Generating high resolution climate change scenarios using PRECIS, Met Office Hadley Centre, Exeter, UK,pp. 40.

NABARD.2014. State Agriculture Plan for West Bengal. Report prepared by NABARD Consultancy Services (NABCONS) on behalf of Agriculture Department, Govt. of West Bengal.249 pp.

Saha, A., (2006). Characterisation of rainwater deficit at growth stages of rainfed kharif rice for timely and delayed transplanting in the new alluvial zone of West Bengal. $J$. Agrometeorol. 8(1): 65-71.

Singh, V.P., and Singh, R.K. (Ed.). 2000. Rainfed Rice: A source book of best practices and strategies in eastern India. International Rice Research Institute, Manila, Philippines.292pp.

\section{How to cite this article:}

Mahato, S., A. Saha and Majumder, D. 2019. Assessment of Water Availability at Growth Stages of Rainfed kharif Rice in the Plains of West Bengal during 2020-2099 using Regional Climate Model Output. Int.J.Curr.Microbiol.App.Sci. 8(04): 2398-2407. doi: https://doi.org/10.20546/ijcmas.2019.804.279 